\title{
Geometria através de hipertextos com animações interativas
}

\author{
Maria Alice Gravina* - gravina@mat.ufrgs.br \\ Marina Menna Barreto ${ }^{* *}$ - marinambarreto@gmail.com \\ Instituto de Matemática, UFRGS
}

Resumo Um dos grandes desafios da educação, provocados, sobretudo pela modalidade a distância, é o desenvolvimento de atitudes, por parte dos alunos, na direção de uma aprendizagem com a autonomia. Na área da Educação Matemática os alunos se defrontam com as dificuldades adicionais quanto ao domínio da linguagem matemática, com seus signos, símbolos e desenhos. Este artigo trata da produção e do uso de hipertextos com animações interativas para curso ofertado na modalidade a distância para professores da educação básica. Os resultados obtidos indicam interessantes possibilidades deste material digital quanto ao processo de aprendizagem da geometria, com autonomia.

\section{Palavras-Chave}

geometria, EAD, processo de aprendizagem, hipertextos e animações interativas

\section{Geometry through hypertexts with interactive animations}

\begin{abstract}
One of the great challenges of the education, especially in distance learning, is the development of student's attitudes for the study with autonomy. In Mathematics Education the students are confronted with an additional difficulty from the domain of the mathematical language with their signs, symbols and drawings. This article talks about the design and the use of hypertexts integrated with interactive animations to be used in a distance learning course for mathematics teachers. The results indicate interesting possibilities of the material in a geometry learning process based on autonomy.
\end{abstract}

\section{Keywords}

geometry, distance learning, learning processes, hypertexts and interactive animations

\section{Introdução}

Um dos grandes desafios da educação, provocados, sobretudo pela modalidade a distância, é o desenvolvimento de atitudes, por parte dos alunos, para uma aprendizagem com a autonomia. Na área da Educação Matemática os alunos se defrontam com adicional e específica dificuldade: o domínio da linguagem matemática, com seus signos, símbolos e desenhos.

Cada vez mais, as pesquisas que tratam de aprendizagem da Matemática fazem referências aos aspectos semióticos, para além da tradicional linguagem formal, que devem ser levados em consideração nos processos cognitivos que concorrem para a construção do

\footnotetext{
*Professora do Curso de Licenciatura em Matemática e do Programa de Pós-Graduação em Ensino de Matemática. Coordenadora do Curso de Especialização Matemática, Mídias Digitais e Didática, do PPGENSIMAT/UFRGS e UAB/MEC.

** Mestre em Ensino de Matemática pela UFRGS e tutora a distância do Curso de Especialização Matemática, Mídias Digitais e Didática, do PPGENSIMAT/UFRGS e UAB/MEC.
} 
conhecimento $^{1}$. Estes aspectos semióticos se evidenciam, especialmente, nas representações dinâmicas e manipuláveis que hoje se descortinam nas telas dos computadores, na forma de figuras, diagramas, sons, objetos metafóricos.

É neste cenário de discussão que vamos apresentar uma experiência de elaboração e uso de material didático digital. O material foi produzido para o Curso de Especialização Matemática, Mídias Digitais e Didática (ESPMAT), que está sendo ofertado na modalidade EAD para professores de Matemática da Educação Básica, através do Programa de Pós Graduação em Ensino de Matemática do Instituto de Matemática da UFRGS e no âmbito do projeto Universidade Aberta do Brasil/MEC. Na próxima seção trazemos algumas reflexões sobre o potencial das mídias digitais como suporte aos processos cognitivos que concorrem para a aprendizagem. O material didático digital, concebido como um hipertexto que integra diferentes animações interativas e voltado para conteúdos de geometria, é apresentado na seção 3. O resultado obtido quanto à eficácia do material para a aprendizagem com autonomia é documentado na seção 4, através da produção dos alunosprofessores, apresentada como parte de trabalho de uma primeira disciplina do Curso, no segundo semestre de 2009.

\section{Sobre os sistemas de representação e a aprendizagem}

É de forma recorrente que vem sendo publicados artigos na área da Educação Matemática tratando da importância a ser dada aos sistemas de representação semiótica e aos aspectos cognitivos a eles associados no processo se aprendizagem da Matemática. Dentre estes, alguns dizem respeito ao papel da dimensão social na apropriação dos signos (Redford, 2001; Gravina, 2008) e estão em sintonia com discussões que também acontecem no âmbito da pesquisa em Matemática. Em interessante artigo, Thurston (1994) destaca o quão mais fácil é ter-se o entendimento de um resultado de pesquisa, quando apresentado em conversa informal, quando se compara com o tempo exigido para redação e para compreensão deste mesmo resultado, se publicado em revista científica. Seu comentário:

[...]Por que existe tanta diferença na discussão informal, na conferência, no artigo? Na discussão informal as pessoas usam canais de comunicação que estão muito além da linguagem matemática formal. As pessoas fazem gestos, desenham figuras e diagramas, usam efeitos de som e usam a linguagem do corpo [...] A matemática em algum sentido usa uma linguagem comum: a linguagem dos símbolos, das definições técnicas, dos cálculos e da lógica. Esta linguagem comunica algumas formas de pensamento, mas não todas as formas de pensamento matemático.

São estes outros canais de comunicação que, junto com a linguagem formal clássica da Matemática, vêm se tornando objeto de pesquisa nos processos de aprendizagem, sob a ampla denominação de sistemas de representação semiótica. Ernest (2006) avança na definição do que seria um sistema semiótico explicitando três componentes: um conjunto de símbolos que são expressos através da fala ou do texto, e do desenho; um conjunto de regras de produção de signos, incluindo aqui aquelas que tratam da organização do discurso que faz uso da composição de signos; um conjunto de relações entre os signos e seus significados, dependente de uma subjacente estrutura de significados.

As mídias digitais ampliam as possibilidades destes sistemas de representação - os quais vamos então denominar de sistemas dinâmicos de representação semiótica. Nestes sistemas, por ex., além das variáveis e relações matemáticas que regem um certo modelo, 
têm-se a iconografia, em profusão na tela, do computador - gráficos, diagramas e objetos metafóricos que registram diferentes aspetos de um conceito matemático. Foi fazendo uso deste dinamismo que Kaput (2008) desenvolveu o projeto "SimCalculus"2 - um micromundo interativo onde os alunos, ainda em idade escolar, trabalham com o conceito de taxa de variação, que usualmente é apresentado nos cursos universitários de cálculo diferencial. É assim, também, que na geometria, através do dinamismo dos desenhos, se evidencia o conceito figural teorizados por Fischbein (1994). Através da clara fusão de seus dois componentes: o componente conceitual, apresentado em linguagem natural e/ou simbólica; o componente figural consistindo de família de desenhos que se apresentam em diferentes posições e tamanhos, mas que são invariantes quanto a propriedade geométrica dada pelo componente conceitual - por ex., no caso de um losango os lados se mantém sempre congruentes.

Vê-se que o dinamismo das representações veiculadas na tela computador, associado à possibilidade de manipulação direta, torna-se um suporte que propicia a fluidez dos processos mentais, de forma incomparável àquela que se consegue com o texto e desenho estático, quer impresso ou feito com giz no quadro negro. Nesta concretização dinâmica tem-se até mesmo a possibilidade de construção de conceitos que, em princípio, estariam fora do alcance cognitivo de sujeitos em idade escolar, como o caso do conceito de taxa de variação referido acima.

É na perspectiva de Levy (1993) que consideramos os sistemas dinâmicos de representação semiótica como tecnologias da inteligência. Por um lado, eles concorrem para interiorização de saberes, isto através de suporte mais versátil - ampliando-se assim o papel dos signos no desenvolvimento das funções psicológicas superiores. Aqui nos colocamos também sob a perspectiva vygotskiana, ao considerarmos os signos como meios que dão suporte a resolução de problemas (comparar, reportar, analisar, escolher, entre outras ações mentais), sendo eles instrumentos para a atividade cognitiva, assim como as ferramentas são instrumentos para o trabalho (Vygotsky, 1978). Por outro lado, estes mesmos sistemas permitem, cada vez mais, externar explorações e investigações que normalmente acontecem nos bastidores da atividade intelectual. E mais, com os avanços dos recursos tecnológicos informáticos, tais sistemas estão incorporando representações de pensamentos que fazem intenso uso de imagens - são os pensamentos de natureza visual que, em diferentes graus, participam de nossos funcionamentos cognitivos. Na pesquisa matemática atual, objetos e processos abstratos até então restritos aos “olhos da mente” são agora externados através de precisas e dinâmicas visualizações na tela de um computador, implicando novas idéias para o entendimento da complexidade de muitos destes objetos e processos. É nesta perspectiva que Palais (1999) desenvolveu software especialmente dirigido ao que ele denomina visualização matemática (mathematical visualization), e nos diz: "conforme a matemática se torna mais e mais complexa, torna-se cada vez mais importante ter ferramentas que suplementem nossa intuição e que nos ajudem a comunicar nossa idéias intuitivas".

É fato que as mídias digitais cada vez mais se integram às nossas atividades - sejam cotidianas, de aprendizagem, de pesquisa ou de diversão - e isto explica as recorrentes reflexões que aparecem na literatura, associadas às expressões paradigmáticas tais como tecnologias da inteligência (cunhada por Levy,1993) ou ferramenta para o pensamento (cunhada por Papert,1993). Nesta direção, e avançando sob um ponto de vista epistemológico, temos a provocativa expressão de Shaffer e Clinton (2006) "ferramentaparapensamentos (toolforthougths)" - cunhada com o propósito de registrar 
uma visão que considera que sujeitos e artefatos tecnológicos podem se colocar em situação de simbiose, em processo mútuo de ação e reação. Ou seja, o artefato também tem o poder de agir sobre o sujeito, daí a expressão que funde as duas palavras. Esta ferramentaparapensamentos estaria sinalizando a criação de uma nova cultura cognitiva humana. Esta cultura estaria em linha de continuidade com a história das culturas da humanidade, que nos seus primórdios desenvolveu, a partir dos gestos físicos, a cultura mimética; com a palavra e as narrativas faladas, a cultura mítica; com o registro da informação escrita na forma de símbolos e a possibilidade de reuso de idéias cria-se a cultura das teorias. E hoje, com a possibilidade de externar processos simbólicos através de mídias computacionais, ainda segundo os mesmos autores, estaríamos entrando na cultura do virtual, para a qual ainda não chegam a apresentar um claro paradigma. Acrescentaríamos, de forma mais específica, que com as possibilidades de internalizar e externar idéias e pensamentos através de sistemas dinâmicos de representação semiótica, os nossos funcionamentos cognitivos se tornam, no mínimo, mais versáteis.

É intencionalmente que nesta seção fizemos considerações que, mesmo sendo muito breves, se aproximam de questões de natureza epistemológica. E justificamos: este contexto nos ajuda a entender o alcance que podem ter as mídias digitais nos processos educativos, se queremos provocar ao máximo as habilidades cognitivas que acompanham as situações de aprendizagem, dentre elas, aquela que busca o domínio dos sistemas de representação que veiculam idéias e novos conhecimentos matemáticos. Neste sentido, os hipertextos que integram animações interativas são interessantes possibilidades de material educativo, especialmente para a EAD. É através da apresentação do material que está sendo produzido para o ESPMAT, que vamos ilustrar algumas destas possibilidades, na próxima sessão deste artigo.

\section{Hipertextos com animações interativas e a aprendizagem da Geometria}

A produção de material na forma de hipertexto permite a criação de ambientes favoráveis ao aprendizado autônomo, pois os recursos de programação permitem a conjugação de navegação com diferentes ferramentas de interação. No entanto, algumas características na estrutura dos sites devem ser observadas para que, de fato, possam atingir os resultados desejados: a estrutura do hipertexto deve ser entremeada de diferentes mídias.

Destacamos as figuras fixas ou dinâmicas e os vídeos que orientam e enfatizam aspectos relativos a conteúdos, trabalhos e atitudes. Tudo isso dentro de uma estrutura não linear que maximize o uso da navegação na definição de percursos que contribuam para o processo de aprendizagem. A navegação também deve ser intuitiva de forma que o aluno possa localizar rapidamente o material desejado.

É dentro dos princípios apresentados acima que está sendo desenvolvido material para o curso ESPMAT, voltado para professores de Matemática da Educação Básica. É uma iniciativa que busca a produção de um material digital que explora diferentes recursos pedagógicos, fundamentada nos objetivos que norteiam o projeto pedagógico do curso, a saber: a atualização dos conhecimentos dos professores de matemática, integrando nisso o uso de mídias digitais na sala de aula; a implementação de práticas-pedagógicas inovadoras nas escolas, contemplando um papel ativo do aluno no processo de aprendizagem, em particular através do uso de mídias digitais.

Para cada disciplina do curso está sendo implementado um site, sempre com a mesma estrutura de navegação. Esta estrutura é muito simples e propicia uma navegação 
fácil, rápida e intuitiva através da barra vertical de "menus" que organiza os módulos de trabalho da disciplina (Figura1). Cada módulo inicia com uma breve apresentação daquilo que será desenvolvido ao longo da semana e está dividido em sub-menus: objetivos - dá o panorama geral do módulo e contém a resposta para a pergunta: “o que estudaremos neste módulo?”; conteúdos - apresenta e desenvolve a teoria e o conhecimento básico da matemática ou da didática que será necessário para a exploração do módulo; atividades sugere atividades a serem desenvolvidas; recursos - propõe o uso de recursos de mídias digitais e que possam ser utilizados em sala de aula e disponibiliza tutorias para ajudar no domínio do recurso; complementos - sugere materiais adicionais, envolvendo os conteúdos matemáticos e/ou didáticos e os recursos apresentados no módulo.

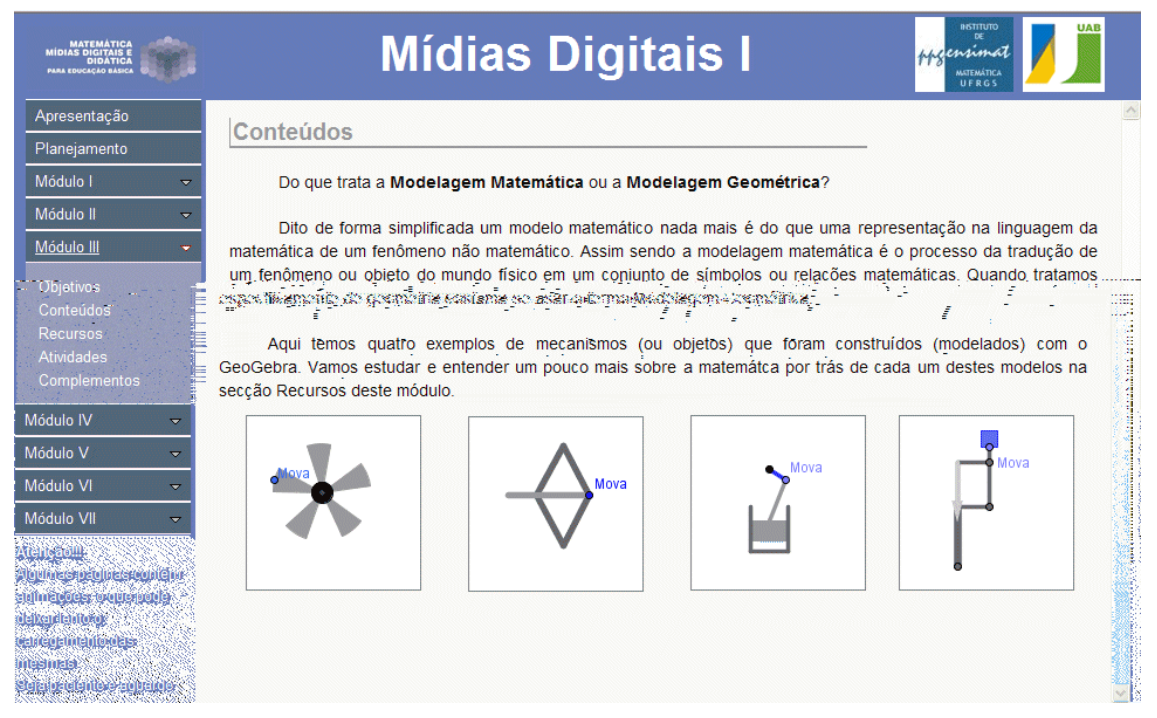

Figura 1: Interface do site da disciplina Mídias Digitais I, com a estrutura de menus e sub-menus e detalhes do material disponibilizado no Módulo III.

As considerações feitas na sessão anterior são, também, explicitações do nosso entendimento da importância da versatilidade dos sistemas de representação semiótica a ser usado em material que é projetado para uma aprendizagem com autonomia. É assim que em cada Módulo procuramos integrar aos hipertextos diversos objetos de aprendizagem ${ }^{3}$ que, na sua maioria, se caracterizam como animações dinâmicas e interativas.

Com o propósito de tornar mais clara nossa proposta, vamos colocar atenção no site da disciplina Mídias Digitais $\mathrm{I}^{4}$, em especial no material que está disponibilizado no Módulo III. É importante mencionar que esta disciplina teve como objetivo a capacitação do professor de escola no uso de mídias digitais (software e objetos de aprendizagem) para a Educação Matemática, incluindo nisso o domínio dos conteúdos matemáticos.

Neste módulo é desenvolvida uma proposta que trata de modelagem geométrica, especialmente em mecanismos com movimentos, e é inspirada na idéia de que o mundo que nos rodeia está repleto de situações em que a geometria se faz presente. Por ser a modelagem matemática um processo de abstração de uma situação ou fenômeno físico pode-se dizer então, que dessa forma faz uso de um sistema de representação semiótica. Em situações de aprendizagem, a modelagem pode ter também o simples propósito de provocar as habilidades cognitivas (conforme veremos nos trabalhos produzidos pelos alunos). E mais, de acordo com Cundy (1997), não há dúvida de que aprendemos e entendemos 
melhor as propriedades de algum modelo quando temos a oportunidade de vê-lo, manipulálo, e mais ainda, construí-lo. É nesta linha de pensamento que foi desenvolvido o material que trata de modelagem geométrica.

No sub-menu "Objetivos" os alunos são inicialmente provocados a observar, em situações cotidianas, mecanismos com movimento já procurando identificar as propriedades geométricas neles presentes. A título de primeiros exemplos, o hipertexto traz figuras de mecanismos como ventilador, macaco de carro, balança, roldana. É então colocado o desafio: como construir réplicas dos objetos, usando o software de geometria GeoGebra?

A transposição do objeto físico para um modelo geométrico exige domínio do sistema de representação no qual são expressos os segmentos, retas, círculos, rotações e translações (entre outros conceitos), de forma a criar no modelo o mesmo movimento do objeto físico. Como esta transposição não é de todo simples, no sub-menu "Conteúdos" disponibilizamos quatro modelos que podem ser manipulados - são animações que incorporam o funcionamento do ventilador, do macaco de carro, do pistão e da balança de prato (Figura 2).
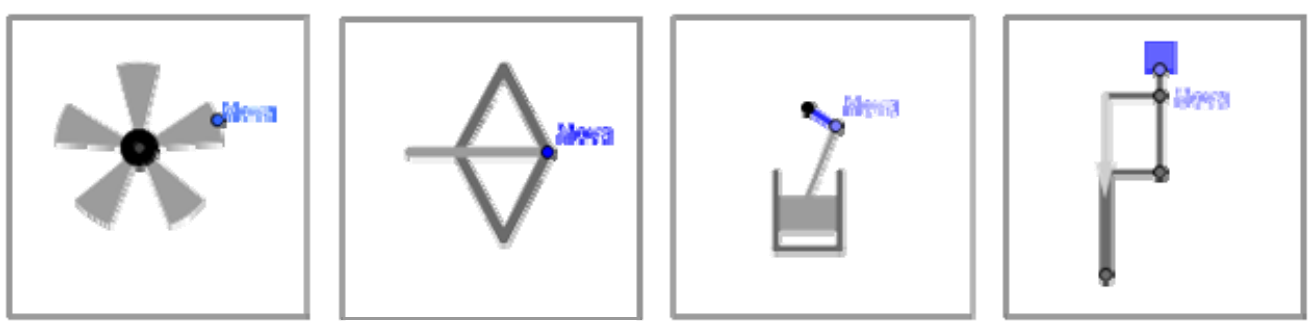

Figura 2 - Modelos geométricos de ventilador, macaco de carro, pistão e balança.

São applets Java ${ }^{5}$ resultantes de construções feitas de tal forma que o movimento de um único ponto (ponto Mova) desencadeia o movimento de todo o mecanismo. Assim o aluno é provocado a entender, no dinamismo do movimento, as propriedades geométricas que foram impostas na construção do modelo. Observamos que, nesta etapa, o aluno está sendo provocado no entendimento de um modelo já construído. A complexidade da construção não é ainda visível e o aluno explora apenas qualitativamente as relações geométricas que se evidenciam no dinamismo. Gravina e Póla (2008) colocam que esta exploração qualitativa é etapa importante no processo de aprendizagem da modelagem. Isto porque variáveis geométricas e relações de dependências devem ser identificadas no modelo, e neste caso, o sistema de representação com desenhos dinâmicos torna-se um importante apoio. A título de exemplo trazemos na Figura 3 o modelo do macaco de carro em diferentes instâncias de movimento. Com um olhar acurado no dinamismo da figura, o aluno pode (e deve) identificar o segmento que se comporta como "raio de círculo girando", pois é a partir deste segmento que se constrói o losango que constitui a estrutura do macaco. 

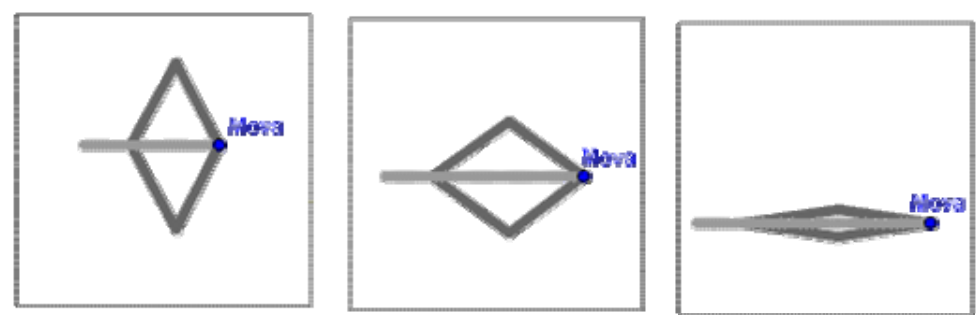

Figura 3: Modelo do macaco de carro. A manipulação do ponto "Mova” dá movimento ao mecanismo. A figura mostra três instâncias do movimento.

Neste ponto, se já confiante nos princípios que regem a modelagem geométrica, o aluno pode se aventurar na construção de seu próprio modelo de mecanismo. O material de estudo, até então, faz uso de sistema dinâmico de representação na concisa forma de "desenhos com movimento". O entendimento da informação exige habilidades cognitivas associadas a pensamentos de natureza visual, e isto pode ser difícil para alunos com vivências em sistemas de representação que fazem uso, sobretudo, do texto e do desenho estático. Neste sentido, o material disponibilizado no site procura atender, de forma gradativa, as dificuldades dos alunos.

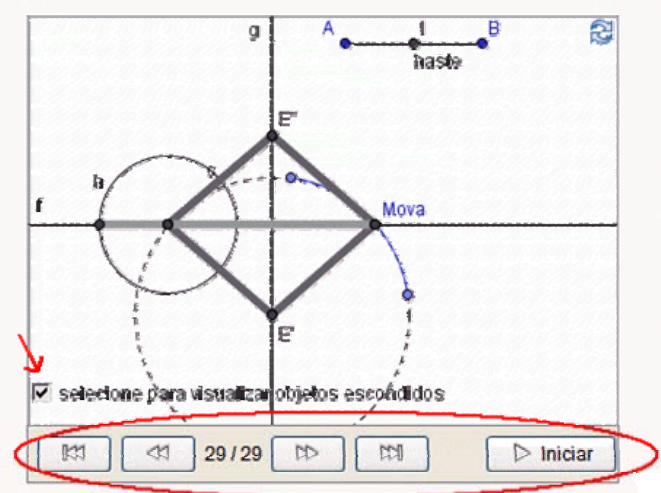

Figura 4: Modelo dinâmico do macaco de carro. A barra de navegação, assinalada, permite o acompanhamento dos passos de construção.

Dando continuidade, o aluno é convidado ao estudo da geometria que está por trás de cada um dos modelos apresentados. Para isto, no sub-menu "Recursos", são disponibilizados objetos de aprendizagem através dos quais é possível explorar o procedimento de construção dos modelos. Na Figura 4 temos o objeto relativo à construção do modelo do macaco de carro. O seu funcionamento pode ser acompanhado "passo-apasso", no seu ritmo de aprendizagem, através da barra de navegação que se encontra na parte inferior do objeto. A todo instante pode-se manipular o ponto "Mova” e usar o dinamismo da figura para o entendimento das relações geométricas que estão sendo construídas. Em particular, observar que o modelo relaciona dois tipos de movimento: o movimento circular do ponto "Mova" e o movimento retilíneo vertical do ponto E (este o ponto em que o carro se apóia no macaco), e isto é garantido pela propriedade que caracteriza o losango - aquela de ter diagonais perpendiculares. 
Essa é a reflexão que se deseja provocar no aluno a partir da exploração do objeto de aprendizagem. Isto porque, é com este entendimento que o aluno pode avançar na construção de outros modelos.

Os objetos de aprendizagem disponibilizados no site apresentam as características elencadas por Willey (2009): ser digital, ter a possibilidade de reutilização e ter intencionalidade quanto à aprendizagem. No caso da modelagem geométrica, os objetos foram concebidos para que os alunos, de forma autônoma, aprendessem geometria e desenvolvessem habilidades para fazer modelagem geométrica. Além disto, na concepção e implementação dos objetos estivemos atentos ao uso de sistemas dinâmicos de representação semiótica, apostando no papel de tais sistemas no desenvolvimento de habilidade cognitivas que enriquecem o "pensar sobre formas geométricas".

\section{Sobre os resultados}

Com o propósito de situar o contexto de uso do material didático digital apresentado na seção anterior, descrevemos brevemente o funcionamento do Curso. As atividades iniciaram em julho de 2009 e ainda estão em andamento, devendo ser desenvolvidas ao longo de 3 semestres. Cada semestre é composto por um conjunto de disciplinas que tratam de conteúdos de matemática, de didática e do uso de mídias.

As diversas disciplinas estão ancoradas no ambiente Moodle-UFRGS e a rotina semanal de trabalho se organiza da seguinte forma: no Moodle os alunos recebem orientações sobre a tarefa da semana, com indicação do material para estudo disponibilizado em Módulo do site da disciplina e com descrição do trabalho a ser entregue. Através de chats, fórum ou mensagens esclarecem suas dúvidas com os tutores ${ }^{6}$.

Foi na terceira semana da disciplina de Mídias Digitais I que os alunos iniciaram seus estudos sobre modelagem geométrica. A tarefa da semana consistia em, inicialmente, explorar e estudar o hipertexto com os objetos de aprendizagem relativos à modelagem do ventilador e do macaco-de-carro, disponibilizado no link "Módulo III" do site da disciplina. Uma vez entendido os procedimentos da modelagem geométrica - para isto explorando os objetos de aprendizagem, sempre que necessário - o aluno deveria produzir uma nova modelagem, escolhendo um mecanismo de seu interesse.

A entrega do trabalho foi feita no espaço "Banco de Dados", no Moodle na forma texto com breve descrição do procedimento de construção e das dificuldades encontradas acrescentado do arquivo do GeoGebra com a construção e ainda imagem (formato jpeg) do modelo construído. A publicação dos trabalhos no Banco de Dados se organiza como uma "Galeria” e assim, em breve vista de olhos, já nos foi possível identificar o importante papel do material disponibilizado na forma de hipertexto com animações interativas. A Galeria descortinou muitos ventiladores e rodas gigantes, mas também outros mecanismos como automóveis, relógios, brinquedos e pontes móveis.

É importante salientar que estes professores-alunos estavam, neste momento, cursando a primeira disciplina do Curso $^{7}$ e, portanto com pouca vivência no uso do GeoGebra. Foi na situação de aprendizes iniciantes que fizeram esta primeira atividade de modelagem, e assim, naturalmente, produções muito simples e parecidas com aquelas exploradas nos objetos de aprendizagem foram apresentadas. Mas também foram feitas modelagens de mecanismos diferentes e mais complexos como, por exemplo, a modelagem de janelas e de portas. 


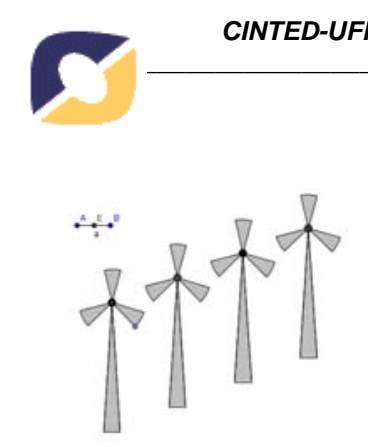

(a)

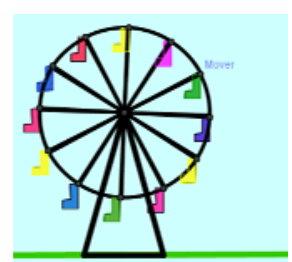

(b)

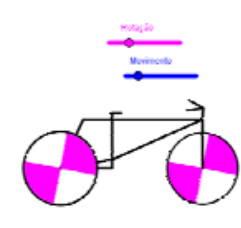

(c)

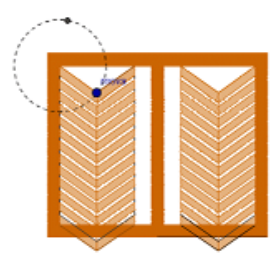

(d)

Figura 5: Situações de modelagem apresentadas pelos alunos.

A Figura 5 traz uma amostra das produções. A modelagem do cata-vento, ilustrada na Figura 5a, não traz muita novidade: os princípios geométricos que garantem o movimento são os mesmos usados na modelagem do ventilador. Quanto ao movimento, o aluno não se aventurou em ir além do que lhe foi ensinado; no entanto integrou, à construção, o movimento de translação para obter o efeito "muitos cata-ventos" (uma situação que lembra o parque eólico da cidade de Osório, RS). Na Figura 5b ainda temos uma reprodução do mesmo movimento circular do ventilador, mas acrescido de detalhes que nos fazem ver uma roda-gigante. Já na Figura 5c temos o modelo de mecanismo bem mais elaborado, embora os movimentos no modelo ainda sejam independentes - a roda gira, mas não se desloca; ou a roda se desloca, mas não gira (a sincronização dos dois exige uma maior desenvoltura para fazer modelagem geométrica). A Figura 5d traz situação em que o aluno conseguiu resolver um problema de modelagem mais complexo, pois agregou o movimento circular e movimento retilíneo que produzem o efeito do “abrir a veneziana”.

Sendo esta a terceira atividade de uma primeira disciplina do Curso, e considerando que os alunos também estavam iniciando primeira experiência em educação a distância, julgamos que os resultados obtidos foram interessantes e animadores. Também é preciso destacar que diferentes competências estavam sendo exigidas, como o domínio de conteúdos de geometria; do software GeoGebra; e dos princípios de modelagem geométrica.

\section{Considerações finais}

Após quase um ano de curso, é possível observar um franco progresso dos alunosprofessores quanto à articulação entre conhecimentos de Matemática, de Mídias Digitais e de Didática. A sistemática disponibilização, para cada disciplina, de site na forma de hipertexto com diferentes recursos - recursos de vídeos e tutoriais também começaram a serem incluídos, além dos objetos de aprendizagem - têm sido uma referência de estudo para os alunos. Com a estrutura de navegação padronizada, eles podem concentrar esforços no avanço de questões que estão no cerne do programa de formação - são as questões relativas a conteúdos de Matemática e de domínio de tecnologia, visando novas práticas escolares.

Essa experiência de produção do material didático para o curso de especialização tem nos mostrado que a educação na modalidade a distância exige material com linguagem de comunicação que seja muito versátil e é assim que procuramos tirar o máximo proveito das imagens visuais, nisso fazendo uso de recursos dinâmicos e interativos. Com a implementação de objetos de aprendizagem, onde sistemas dinâmicos de representação semiótica estão presentes, estamos também contribuindo para provocar o desenvolvimento de habilidades cognitivas que serão cada vez mais necessárias na cultura do virtual. 


\section{Notas}

${ }^{1}$ Ver a revista Educational Studies in Mathematics, vol 61, n. 1-2, 2006.

${ }^{2}$ Endereço do projeto SimCalc é http://www.simcalc.umassd.edu/.

${ }^{3}$ Estes objetos foram implementados com o software de domínio público, GeoGebra. É um software geometria dinâmica, pois as figuras nele construídas, se com princípios geométricos, mantém suas propriedades quando seus pontos são movimentados. Endereço: http://www.geogebra.org/cms/.

${ }^{4} \mathrm{O}$ material do site foi concebido e implementado pelas professoras Maria Alice Gravina e Marina Menna Barreto, com o apoio de Mariângela Torre Dias. Disponível em http://www6.ufrgs.br/espmat/.

${ }^{5}$ Foram construídos e transformados em animação Java no GeoGebra.

${ }^{6}$ O professor de cada disciplina é o responsável pela concepção do material a ser disponibilizado no correspondente site e pela condução das estratégias de ensino da disciplina. Junto ao professor atuam tutores a distância, responsáveis pelo acompanhamento de uma turma de alunos, que sob a orientação do professor, mediam e orientam as atividades através do Moodle.

${ }^{7}$ Durante dois meses os alunos cursaram a disciplina Alfabetização para EAD, para a capacitação no uso do Moodle e de editores para texto e imagem. No terceiro mês iniciou a disciplina Mídias Digitais I.

\section{Referências Bibliográficas}

CUNDY, H. MARTYN; ROLLETT, A. P. Mathematical Models. Tarquin, 1997.

ERNEST, P. A semiotic perspective on Mathematical Activity. Educational Studies in Mathematics, vol. 61, Dordrecht: Kluwer Academic Publisher, 2006.

FISCHBEIN, E. The theory of figural concepts, Educational Studies in Mathematics, vol. 24/2, Dordrecht: Kluwer Academic Publisher, 1994.

GRAVINA, M. A. . Drawing in movement and insights for the proof process. IJCEELL-International Journal of Continuing Engineering Education and Life Long Learning, v. 18 (5-, p. 564-574), 2008.

GRAVINA, M. A.. Dynamical visusl proof: what does it mean?. XI International Congress on Mathematical Education, Mexico, 2008. Disponível em http://tsg.icme11.org/tsg/show/23\#innerdocuments. Acesso em 28 de maio de 2010.

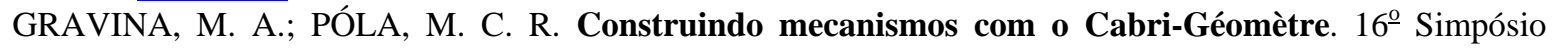
Nacional de Geometria Descritiva e Desenho Técnico. Santa Cruz do Sul, RS, 2003.

KAPUT, JAMES. Building intellectual infrastructure to expose and understand ever-increasing complexity. Educational Studies in Mathematics, V.70, N.2, 2008.

LEVY, P. Tecnologias da Inteligência: o futuro do pensamento na era da informática. São Paulo SP : Editora 34, 1993.

PALAIS, R. The visualization of mathematics. Notices of the MAS, vol. 46, nº 6, 1999, p. 657.

PAPERT, S. The Children Machine: Rethinking Scholl in the Age of the Computers. New York USA : Harvester Wheatsheaf, 1993

RADFORD, LUIS. On the relevance of Semiotics in Mathematics Education. $25^{\text {th }}$. PME International Conference, The Netherlands, 2001.

SHAFFER, W. DAVID; CLINTON A. KATHERINE. Toolforthoughts: Reexamining Thinking in the Digital Age. Mind, Culture and Activity, 13(4), California, 2006.

Thurston, W. On Proof and Progress in Mathematics. New York: Bulletin of The Americam Mathematical Society, vol. 30, no 2, 1994.

VYGOTSKY, L. S. Mind in society: The development of higher psychological process. Cambridge, MA: Harvard University Press, 1978.

WILEY, D. A . Connecting learning objects to instructional design theory : a definition, a metaphor and a taxonomy. Disponível em :http://reusability.org/read/chpters/wiley.doc. Acesso em 27 de maio de 2009. 